\title{
Psychosocial burden of localised cutaneous Leishmaniasis: a scoping review
}

\author{
Issam Bennis ${ }^{1,2,3^{*}}$ (D), Vincent De Brouwere ${ }^{2}$, Zakaria Belrhiti ${ }^{1,2,4}$, Hamid Sahibi ${ }^{5}$ and Marleen Boelaert ${ }^{2}$
}

\begin{abstract}
Background: Cutaneous Leishmaniasis (CL) is a parasitic skin disease, linked to poverty, and belonging to the group of Neglected Tropical Diseases. Depending on the severity, the type of lesions or scars, and the context, $\mathrm{CL}$ can lead to self- and social stigma influencing the quality of life and psychological well-being of the patient. This dimension is, however, little documented for the most common, localized form of cutaneous leishmaniasis (LCL). We aimed to describe the current knowledge on the psychological burden and the stigma related to LCL.

Methods: The population of interest for this scoping review are patients or their relatives with localized LCL or related scars.

We searched the electronic databases PubMed, Web of Knowledge, PsycINFO, POPLINE, Cochrane Library, Science Direct, Global Health, and LILACS, for articles written in Arabic, English, French, Dutch, Portuguese, or Spanish, and published until the end of August 2017.

Results: From 2485 initial records, 15 papers met our inclusion criteria. Dermatology life quality index was the most frequent used scale to assess LCL psychological impact in quantitative studies. Six qualitative studies used individual interviews and/or focus groups discussions to explore the psychological and/or the social burden of this disease. Quantitative assessments using standard scales as well as qualitative research asserts that LCL is a source of psychological suffering, stigmatization, and decreased quality of life (QoL).

Conclusion: Most studies showed that LCL has a significant negative effect on the QoL and mental health. However, the fact that the psychosocial burden generated by LCL is time-dependent makes it hard to measure. We recommend to develop a more specific and validated assessment scale to appreciate the full burden of this disease and enhance comparability of findings.
\end{abstract}

Keywords: Cutaneous leishmaniasis, Cicatrix, Psychology, Social stigma, Quality of life

\section{Background}

Cutaneous leishmaniasis (CL), a neglected tropical disease (NTD), is a parasitic infection of the skin characterized by slowly healing ulcers that can leave indelible scars. There are various clinical presentations of CL: localized, diffuse, disseminated and mucocutaneous CL.

The global mean age-standardized disability-adjusted life years (DALYs) lost by CL were estimated at 0.58 per 100,000 people [1]. However, several authors have criticized the way the global burden of disease tools, such as

\footnotetext{
* Correspondence: issambennis@gmail.com

${ }^{1}$ National School of Public Health, Ministry of Health, Lemfedel Cherkaoui

Street, Madinat Al Irfane, 10000 Rabat, Morocco

${ }^{2}$ Department of Public Health, Institute of Tropical Medicine, Antwerp,

Belgium

Full list of author information is available at the end of the article
}

DALYs, have quantified the burden of CL. A recent viewpoint drew attention to the fact that only active forms of CL are included in DALY calculations. It suggests to consider also the psychological impact linked to the disfiguring scars of CL [2]. Moreover, the same authors proposed to multiply by ten the actual burden of $\mathrm{CL}$, to take into account the effect of CL scars [2]. Under this scenario, the global number of people living with LCL scars is estimated at 40 million. Such claims call for a higher prioritization and resource allocation to CL [2].

Localized CL (LCL) is by far the most common presentation, usually as a single papular or nodular skin lesion that progressively ulcerates and self-heals within a few months [3]. 
In 2013, LCL was primarily reported from 15 countries: Afghanistan, Algeria, Brazil, Colombia, Honduras, Iran, Morocco, Nicaragua, Pakistan, Peru, Saudi Arabia, Syrian Arab Republic, Tunisia, Turkey and Yemen [4].

LCL is often presented in the literature as a dermatological disorder that is "associated with stigma" and psychological suffering, which is quite obvious for the severely mutilating or disseminated types of CL. Severe scar tissue from any cause (acne, burn, injury, Buruli ulcer, lymphatic filariasis, podoconiosis, a.o.) reduces the quality of life in a direct way but also through a process of social rejection and self-depreciation [5-13]. In some skin disorders, this psychosocial effect is predominant, as in vitiligo patients, who experience a reduced quality of life because of their social rejection [14-18]. The psychological distress generated by skin ailments is complex and depends on the severity and visibility of the lesions. Skin disorders are no exception to the general rule that the degree of fear inspired by a disease is mainly associated with the perception of severity and also lack of adequate treatment [19]. In the past, the typical examples were smallpox and leprosy that led to a total isolation of those affected, and more recently, Ebola, HIV/AIDS, psychiatric and mental illnesses continue to generate this stigmatizing behavior in many communities. The resulting social isolation affects a human being psychologically and this was shown in the case of the recent Ebola epidemic to have a negative impact on survival [20, 21]. However, the experience in psoriasis shows that the relationship between symptom severity and psychosocial distress reported by psoriasis patients is not straightforward [22]. Nevertheless, a systematic review showed that clinical depression was 1.5 times more frequent in psoriasis patients than in non-affected peers [23].

In the literature on the psychosocial burden of disease, stigma is a central concept. Mostly stigma manifests itself in discriminatory attitudes against those who are different and is related both to the conception of the 'other' as well as the 'me' [24]. This conceptual complexity makes stigma difficult to determine. Goffman defines stigma as: 'The phenomenon whereby an individual with an attribute which is deeply discredited by his/her society is rejected as a result of the attribute. Stigma is a process by which the reaction of others spoils normal identity' $[19,25]$. Other authors define stigma as a social process that is characterized by exclusion, rejection, and blame resulting from the anticipated perception or expression of an adverse social judgment about a person or a group $[26,27]$. This judgment can be related to the mental disorder, ethnicity or physical handicap of the stigmatized persons [25]. Stigmatisation also affects people who are not perceived as a threat to others but who present a disfigured body $[28,29]$. The judgments made are often the result of comparisons to a perfect, idealized body image [30]. Often shaped on the pictures of 'celebrities' as the ideal social appearance, this idealized body image increases the pressure on those who appear different, pushing some of them to seek cosmetic surgery [31]. Stigma is also typically attached to those conditions in which people are blamed for their appearance [32]. The social rejection generates suffering, as the stigmatized person interiorizes what others think of her/him, leading to loss of self-esteem and what is called "self-stigma" [33]. Once the individual perceives the stigma, it can affect his/her quality of life [15]. The more general concept of "stigma" has, therefore, two dimensions: how others relate to the stigmatized person and how that person relates to him/herself. Henceforward in this text, we distinguish these two dimensions based on the model presented previously by Deacon [34] and adapted by Weiss in 2008 [27]:

1. Social stigma (public stigma) occurs when society actively adopts negative attitudes of rejection or exclusion against the stigmatized who undergo inequitable or discriminatory treatment. Enacted stigma, which is about passive discrimination, is one expression of social stigma. Even if some people disagree with the stigmatizing behaviors of others, they often remain passive about it, without trying to stop it.

2. Self-stigma is an internalized mechanism in the stigmatized person, who is anticipating the social rejection or is adapting to a stigmatizing environment. In this category, we can include: felt stigma, experienced stigma, internalized stigma, internal stigma, anticipated stigma, imagined stigma, perceived stigma.

Then, whether the painless nodules, ulcers, and scars of LCL contribute to the global burden of CL beyond the local discomfort they generate is an open question. So far, little research has been done to underpin this general statement about LCL, nor to differentiate the burden according to CL type.

Our review aimed to describe the current evidence related to the psychosocial burden of LCL. More specifically, our objectives were to (i) explore which quantitative scales were used to assess this burden; (ii) summarize qualitatively the extent of psychosocial suffering (specifically self-stigma, social stigma, quality of life) attributable to LCL. Our research question was "Do persons experiencing a LCL skin lesion suffer from any psychosocial burden?”

\section{Methods}

A scoping review is mainly based on a preliminary assessment of the amount/the extent of available research 
in the literature [35]. Following Arksey and O'Malley's framework we worked through five stages, listed hereafter. Stage 1: identifying the research question; Stage 2: identifying relevant studies; Stage 3: study selection; Stage 4: charting the data; Stage 5: collating, summarizing and reporting the results [36, 37].

\section{Inclusion and exclusion criteria \\ Inclusion criteria}

Population: Persons (patients or their relatives) experiencing a skin condition linked to LCL.

Range of concepts: LCL-related stigma and its psychological consequences in different LCL skin conditions, including LCL scars.

Context: All countries.

All articles discussing entirely or partially the stigma types, psychological and social consequences and quality of life, psychological or psychosocial effects related to Leishmaniasis skin condition. All types of publications were eligible: original articles, literature review, editorial, comments, correspondence, abstracts of workshop or conferences, grey literature, as available online.

\section{Exclusion criteria}

As listed in Additional file 1, we excluded articles for which no full text was available; books; articles targeting veterinary studies, vectors, laboratory or in-vitro research; studies describing CL epidemiology, outbreaks or trends without or with a little indirect information about psychosocial outcomes; articles exclusively targeting HIV or mental illness or other stigmatising diseases without any link with CL; articles treating only the visceral form of leishmaniasis or post dermal kala azar form or exclusively the CL mucosal or tegumentary form; articles on diagnostic methods for $\mathrm{CL}$; treatment assessment or methods not targeting psychosocial interventions in CL (e.g. drug effectiveness).

\section{Search strategy}

Eight databases were selected: PubMed, Web of Knowledge, Science Direct, PsycINFO, POPLINE, LILACS, Global Health CABI and Cochrane Library. We searched these databases from their inception until the end of August 2017 with language restriction to Arabic, English, French, Dutch, Portuguese, and Spanish.

The search in the PubMed and Web of Knowledge databases followed the three steps recommended in Peters et al. [38]. (1) Firstly, we did a limited exploratory search in PubMed combining three keywords: Cutaneous leishmaniasis AND (Stigma OR Quality of life). Then, we built a logical grid after analyzing text words contained in the title and abstract with adding the subject heading and index terms. (2) Secondly, we organized them into blocks by using the advanced search composed of $\mathrm{MeSH}$ terms and free synonymous words categorized into three blocks (1\#Population, 2\#Concept, 3\#Context) which helped us to build the query question and perform the primary search strategy (as listed below). For the other databases, shorter search equations were set to find relevant references to our topic (See Additional file 1).

(3) Thirdly we performed a hand search on the reference list of the selected articles and searched for any publication by the first, second, third and last authors in those selected articles and meeting the same inclusion criteria but initially not detected by our initial search strategy. Also, we looked for overall articles that cited the ones we selected. We repeated this process iteratively until no other relevant articles were found.

\section{Query search (PubMed) and (web of knowledge)}

This search strategy was done end of September 2016 and updated on 1st September 2017.

(((Leishmaniasis OR Dermal Leishmaniasis OR Cutaneous Leishmaniasis OR Mucocutaneous Leishmaniasis OR Diffuse Cutaneous Leishmaniasis NOT Visceral Leishmaniasis)) AND (Social problems OR Public opinion OR Social discrimination OR Social isolation OR Social exclusion OR Social distance OR Stereotyping OR Social perception OR Social conditions OR Social adjustment OR Social behavior OR Social behaviour OR Social behavior disorders OR Social environment OR Social support OR Social marketing OR Cost of illness OR Stigma* OR Public stigma OR Social Stigma OR community stigma OR Enacted stigma OR Self-stigma OR Self stigma OR Experienced stigma OR Perceived stigma OR imagined stigma OR Anticipated stigma OR Felt stigma OR Self-report OR internalized stigma OR Health related stigma OR Gender Identity OR Quality of Life OR Perception OR Rejection OR Discrimination OR Parasitic skin diseases/psychology OR Skin diseases, bacterial/psychology OR Neglected Diseases/psychology OR Psychosocial OR Psycho-social)) AND ((“1920/01/ 01”[PDat]: “2017/08/31”[PDat]) AND (Arabic[lang] OR English[lang] OR French[lang] OR Dutch[lang] OR German[lang] OR Spanish[lang]))

\section{Data collection, extraction, and analysis}

Two investigators (IB, ZB) independently reviewed the titles and abstracts of all retrieved records and selected the articles for full-text review based on eligibility criteria as defined below. EndnoteX7 (Thomson Reuters 2014) was used as a reference manager software. This software served to avoid duplication, achieve the first screening of titles or titles and abstracts, download and manage full texts of selected references for a complete reading step and provide a digital backup for archiving and enhancing traceability of the search process for this review. In case of disagreement, the last author (MB) 
served as the tiebreaker. The other authors, all experts in the field of CL, stigma and conducting systematic reviews, rechecked the inclusion and exclusion criteria of selected articles.

The results of the literature search are presented in a flow diagram (Fig. 1) describing the scoping review process [38]. The Additional file 1 includes more details on the search: activities performed with date, the query equation employed, and the reference list found, including justification for excluding references after full-text reading and the final references of the included articles.

We extracted the data and mapped them in an Excel sheet (Windows, Microsoft Corporation). We used a narrative synthesis approach to compile the data and examples from individual studies. We focused on how studies addressing a different aspect of the same phenomenon can be narratively summarized to provide a bigger picture of that phenomenon. Using Nvivo11 QRS International, we classified them under main conceptual categories (Additional file 1).
We followed the five steps of reporting scoping reviews and used the PRISMA flowchart for reporting the search strategy [36, 37, 39].

\section{Results}

\section{Included papers}

We included 15 articles matching our criteria for a full review (Table 1) [40-54]. The studies were done in nine countries: Afghanistan, Iran, Morocco, Sri Lanka, Surinam, Syria, Tunisia, and Yemen. Nine papers used quantitative research methods, including eight cross-sectional descriptive surveys and one randomized controlled trial of a psychotherapy intervention in LCL. One was based on mixed methods while five were based on qualitative research: one of them was based on focus group discussions, one was a review, and the others were based on interviews.

\section{Psychosocial burden of LCL measured quantitatively}

Anxiety and depression: Seven quantitative studies measured the psychosocial outcome on a standard scale

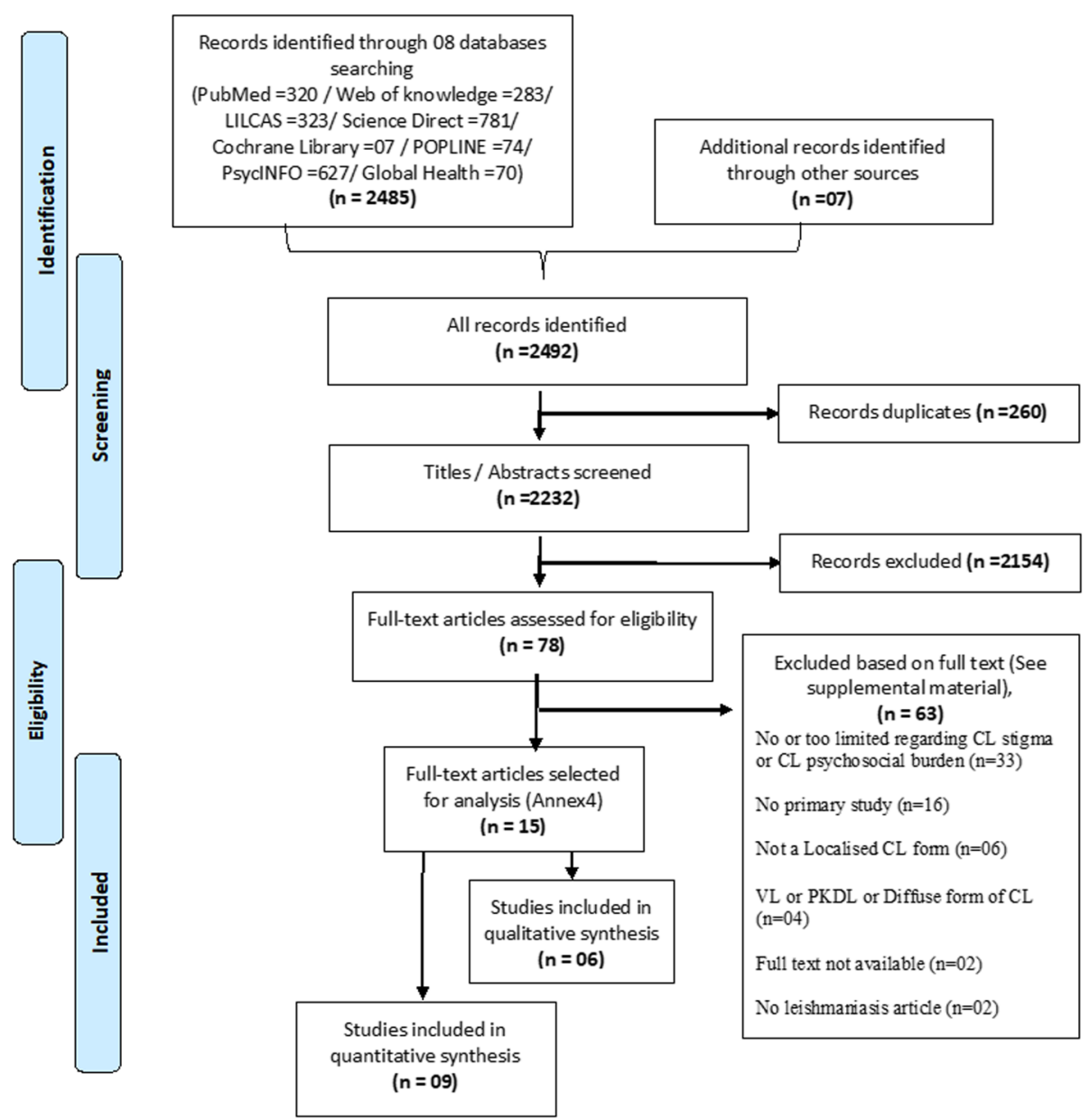

Fig. 1 Flowchart of the number of literature searched and selected for psychosocial burden of Cutaneous Leishmaniasis 


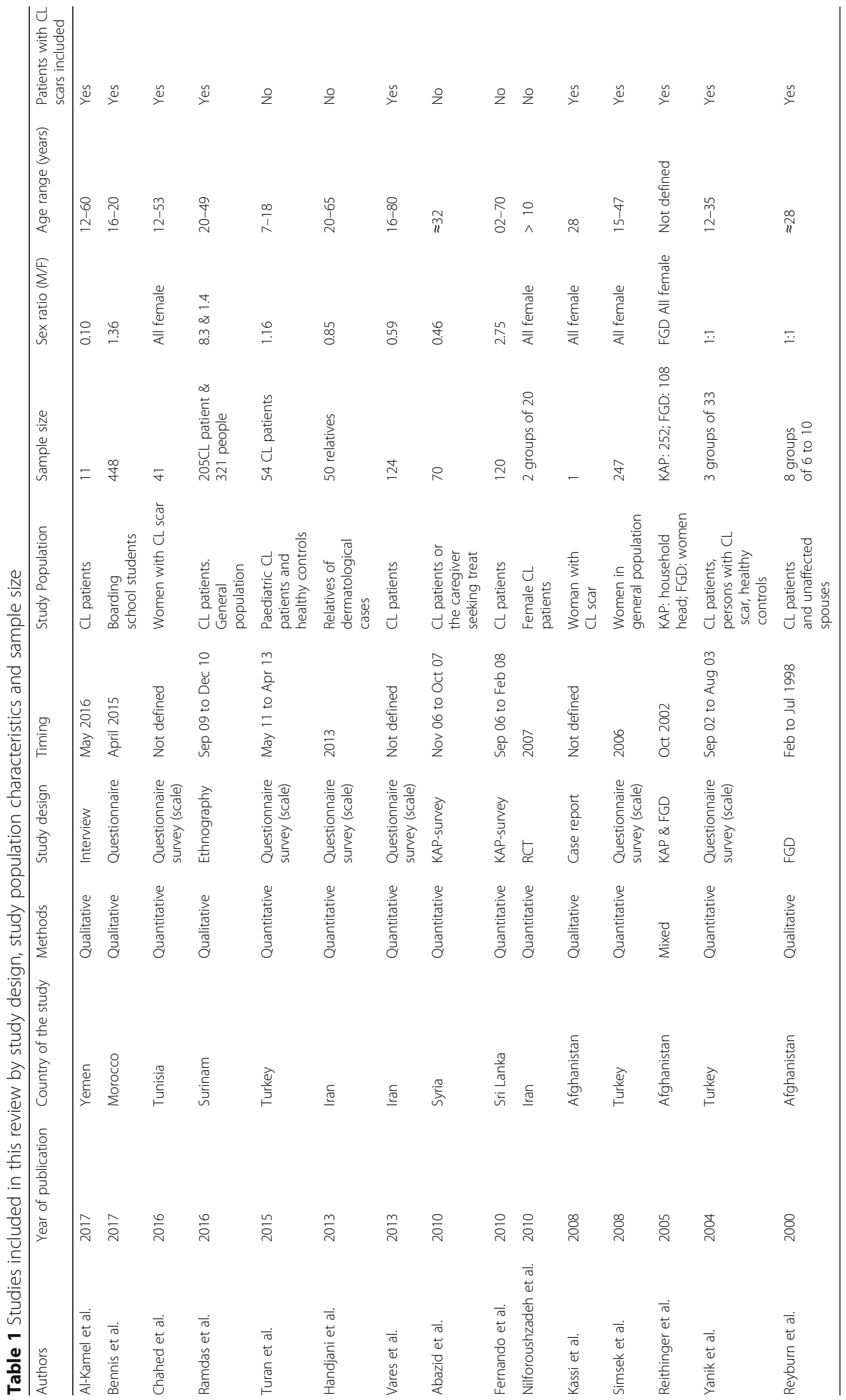


(Table 2). Yanik et al. [41] assessed the psychological impact of LCL in three groups of patients in Turkey (LCLactive lesions, LCL-scars, and a control group). They used three different scales to quantify 1 . Anxiety and depression (HAD), 2. Body Image Satisfaction (BIS), and 3. Dermatology Life Quality Index (DLQI). They concluded that anxiety and depression were frequent symptoms in patients with LCL at both the active lesion and scar stage and affected their quality of life. Patients with LCL scars had better quality of life scores than those with active lesions. Simsek et al. [43] in Turkey used the DSM classification scale of mental illness (DSM-IV) to study predictors of mental disorders in a sample of women from a rural South-eastern region in Turkey. In multivariate analysis, LCL was found to be an independent predictor of mental illness (Odds Ratio (OR) 2.15, 95\% C.I. 1.25 to 7.31$)$ at the same level as domestic violence (OR 2.03, 95\% C.I. 1.17 to 4.28 ). In 2015, Turan et al. [50] in the same endemic area in Sanliurfa, used four scales in children and adolescents from 7 to 18 years and their parents. In the patients with LCL, depression scores were significantly higher than in the control group, and this was also the case in the group of mothers of children with LCL. No difference was found in anxiety scores.

Low quality of life: Two studies were conducted in Iran $[45,48]$ using the DLQI scale to assess the QoL in LCL patients under treatment. Vares et al. [48] found that the type of LCL lesion had a significant effect on the patient's QoL. The DLQI score in patients with papular LCL lesions was better than in those with nodular and plaque lesions. Those with ulcerated lesions had the lowest QoL score. Nilforoushzadeh et al. [45] randomly allocated 40 women with LCL active lesions to either the standard LCL treatment or standard treatment plus psychotherapy. The intervention arm showed a more pronounced improvement in DLQI score at the end of the study after 8 weeks $(p=0.001)$. Hanjdani et al. [49] used the Family DLQI scale to assess the impact of chronic skin disorders on family members. A variety of chronic skin disorders of at least one-month duration (vitiligo, pemphigus, psoriasis, and LCL) were included. There was a reduction of QoL, without a significant difference between disorders, but the sample size was small. The main problems mentioned were emotional distress, spending much time with the patient, and reactions of the others to the patient's condition. The main complaint in families with a LCL case was about the time spent looking after the patient.

Stigma: In Tunisia, Chahed et al. [52] assessed the level of stigma (using the Psoriasis Life Stress Inventory and QoL (Revised Illness Perception Questionnaire and the World Health Organization QoL26) in a sample of 41 women with LCL scars and reported a wide range of psychological effects. 73\% of the women had suffered social exclusion and stigmatization. They reported broken relationships, interpersonal conflicts, reduced employment opportunities, and reduced marriage prospects for men and women. LCL was a constant source of stress for the study participants. They thought their scars were degrading, and a source of shame. The "experience of social rejection" and the "anticipation and avoidance of stress" were significantly and negatively correlated with age. The younger the person, the more impact CL had

Table 2 Overview of the quantitative studies included in this review based on scales questionnaire surveys

\begin{tabular}{|c|c|c|}
\hline Reference & $\begin{array}{l}\text { Measurement scales of psychological, social and QoL } \\
\text { burdens }\end{array}$ & Main findings \\
\hline Chahed-2016 & $\begin{array}{l}\text { Revised Illness Perception Questionnaire (IPQ-R), } \\
\text { World Health Organization Quality of Life-26 (WHO- } \\
\text { QOL-26) }\end{array}$ & $\begin{array}{l}\text { Large range of negative psychological consequences of LCL it is a source } \\
\text { of constant stress and shame. Leading to social rejection and anticipation/ } \\
\text { avoidance behaviour. }\end{array}$ \\
\hline Turan-2015 & $\begin{array}{l}\text { The Child Depression Inventory (CDI) } \\
\text { The State-Trait Anxiety Inventories for Children } \\
\text { (STAIC), } \\
\text { The Paediatric Quality of Life Inventory Parent and } \\
\text { Child Versions (PedQL-P and C) }\end{array}$ & $\begin{array}{l}\text { Depression scores were significantly higher in children and adolescents } \\
\text { with CL compared to age-matched controls. No significant difference was } \\
\text { found in anxiety scores. Depression scores were also higher in mother of } \\
\text { children with LCL. }\end{array}$ \\
\hline Handjani-2013 & Family Dermatology Life Quality Index (FDLQI) & $\begin{array}{l}\text { Family members of } L C L \text { cases face reduction in } Q o L \text {, mainly due to the } \\
\text { time they have to spent looking after the patient }\end{array}$ \\
\hline Vares-2013 & Dermatology Life Quality Index (DLQI) & $\begin{array}{l}\text { The type of } L C L \text { lesion determines the degree of } Q \circ L \text { reduction. Most } \\
\text { reduced in ulcers, least in papular } L C L\end{array}$ \\
\hline $\begin{array}{l}\text { Nilforoushzadeh- } \\
2010\end{array}$ & Dermatology Life Quality Index (DLQI) & $\begin{array}{l}\text { The effect of adjunct psychotherapy to drug treatment on QoL was tested } \\
\text { in a randomized controlled trial on women with } L C L \text {. QoL was improved } \\
\text { in the intervention group. }\end{array}$ \\
\hline Simsek-2008 & $\begin{array}{l}\text { The Turkish version of the Structured Clinical } \\
\text { Interview for Axes I of the DSM-IV (SCID-I) }\end{array}$ & $\begin{array}{l}\text { This study on mental health of women in rural Turkey identified } C L \text { as one } \\
\text { of the main independent predictors of mental disorders }\end{array}$ \\
\hline Yanik-2004 & $\begin{array}{l}\text { Hospital Anxiety Depression Scale (HAD), } \\
\text { Body Image Satisfaction Scale (BIS), } \\
\text { Dermatology Quality of Life Scale (DQL) }\end{array}$ & $\begin{array}{l}\text { Depression and anxiety are higher in } L C L \text { compared to control. Impaired } \\
\text { body satisfaction in } L C L \text {. } L C L \text { have reduced } Q \text { Q compared to } L C L \text { scars } \\
\text { and controls. }\end{array}$ \\
\hline
\end{tabular}


in terms of stigma. QoL was correlated with the "anticipation of stress" score but negatively correlated with knowledge about CL. The more a person knew about LCL, the less likely they were to view their quality of social life negatively.

Fear of scars: The two other quantitative studies included in this review $[46,47]$ were both based on a general questionnaire targeting knowledge, attitudes, and practices of LCL patients in endemic areas from Syria and Sri Lanka. In both studies, no direct information about QoL was provided except the adverse effect of fear about LCL scars, especially on the face.

\section{Psychosocial burden of $L C L$ reported qualitatively}

Very recently five qualitative studies provided more information on the CL psychosocial burden from the perspective of the general population and affected patients living in LCL endemic areas (Table 3).

Expectation of stigmatisation: The most important effects were linked to LCL patients holding scars on visible parts of their body, specifically on women faces' more than men. Chahed et al. [52] reported feelings of inferiority and the idea that the disease is equal to an apparent social disadvantage. Fifty percent of all women with scars said scars alter their beauty.

Perception of changed body image: The concept of loss of beauty has been a frequent feature of all these studies, especially for young bachelors. The impact of unwanted changes in body image is considered as a curse or bad luck that will diminish the marriage opportunities of the person suffering from LCL scar.

Self stigma: A broad spectrum of psychosocial suffering was reported such as being shy, ashamed, stressed, anxious, depressed. Feeling embarrassment, sadness, suicidal thoughts and decrease of self-concept (self-confidence, self-esteem, self-contempt, self-awareness) lead patients to perceive or interpret negatively some direct or indirect reactions from partners, relatives, and the general population.

Some women affected by LCL try to hide their lesions from their partner and look for more permanent solutions by surgical repair or aesthetic surgery. As Chahed et al. [52] have pointed out, the extent of the stigma that patients experience is associated with their anticipation of rejection.

Social stigma: From emotional isolation and emotional distress to firm social rejection and discrimination within the same household, with friends or/and workmates, or abroad family visitors. Some affected people felt their chances to find employment, studies or marriage jeopardized. However, simultaneously, the perceived stigma which was expressed or enacted by the neighborhood led to psychological consequences as well. In Afghanistan [40], women with LCL frequently felt rejected. As LCL was relatively new in Kabul, there was a widespread misconception about its origin, with fear of contagion and an association of LCL with dirt and low personal hygiene. People attributed LCL to "the fault and sin carried by strangers living in neighboring provinces or cities." Such misconceptions raise the level of rejection and social exclusion.

Mitigating factors of stigma (Resistance to stigma): The tendency to isolate LCL patients from others contributes to more self-stigma. The patients try to hide or mask the lesion, by using homemade or commercial makeup, or by wearing the traditional veil. The qualitative studies also reported that LCL being for some people only a minor source of suffering, for the following reasons. Firstly, people living in rural areas consider it quite normal to have scars because of the forestry and agriculture activities which expose them to several abrasions and wounds. Thus, an ulcer that self-heals over time is not a major problem for them. Such scars are sometimes even considered as a mark of belonging and membership to a community, even as a mark of glory and pride. Secondly, religious people tend to accept this kind of ailments, as a submission to the will of the Almighty. Finally, old people have less fear about aesthetic outcomes than younger people.

\section{Discussion}

The main finding of our review is that LCL indeed generates psychological suffering and mental ill-health, as shown in several countries. LCL leads to social stigma that eventually causes self-stigmatization, which amplifies the feelings of fear, anxiety, and depression in those affected. Extreme self-isolation and self-contempt can sometimes even lead to suicidal ideation. Moreover, young single women with facial scars face the most substantial psychosocial impact of LCL [40, 52, 54, 55]. Of course, there is a contrast with the ill-health generated by the more severe diffuse, disseminated and mutilating mucocutaneous CL forms, which can even be lifethreatening. Getnet's work in Ethiopia [56] and in Latin America [57-61] showed the psychosocial burden of these non-localized CL types for which the prognosis is much more severe than that of LCL.

Our review adds some new insights to the stigma theory presented previously for HIV by Deacon \& al [34] and adapted for neglected tropical diseases by Weiss in 2008 [27]. We elaborated further on this model by including the reflection about body image and its distortions presented by Thompson \& al [62]. We also introduced "change over time" as an important determinant for the perception of the severity and the psychosocial impact of any acquired skin disorder. Time adjustments influence the degree of self-stigma on the one hand, and on the other hand also influence the 
Table 3 Overview of the included studies analysed qualitatively

\begin{tabular}{|c|c|c|c|}
\hline $\begin{array}{l}\text { 1st Author } \\
\text { name, Year of } \\
\text { publication and } \\
\text { country of the } \\
\text { study. }\end{array}$ & $\begin{array}{l}\text { Types of stigma } \\
\text { noticed }\end{array}$ & $\begin{array}{l}\text { Types of psychological consequences } \\
\text { related to CL }\end{array}$ & Reasons for stigma \\
\hline $\begin{array}{l}\text { Al-Kamel-2017 } \\
\text { (Yemen) }\end{array}$ & $\begin{array}{l}\text { Social stigma } \\
\text { Aesthetic stigma } \\
\text { Psychological } \\
\text { stigma }\end{array}$ & Stress Depression Anxiousness Shame & Socially isolated \\
\hline $\begin{array}{l}\text { Bennis-2017 } \\
\text { (Morocco) }\end{array}$ & $\begin{array}{l}\text { Self-stigma Social } \\
\text { stigma }\end{array}$ & $\begin{array}{l}\text { Large spectrum of negative psychosocial } \\
\text { effects: Anxiety, Embarrassment, Sadness, } \\
\text { Shame, Suicidal ideas }\end{array}$ & $\begin{array}{l}\text { Social stigma (Family relationships, social } \\
\text { contempt, fear, marriage difficulties, } \\
\text { avoidance by others). Self-stigma (embar- } \\
\text { rassment, shame, sadness, anxiety, depres- } \\
\text { sion, suicidal ideas) }\end{array}$ \\
\hline $\begin{array}{l}\text { Chahed-2016 } \\
\text { (Tunisia) }\end{array}$ & $\begin{array}{l}\text { Social exclusion } \\
\text { and } \\
\text { stigmatization }\end{array}$ & $\begin{array}{l}\text { Loss of self-esteem, feelings of } \\
\text { inferiority and the idea that the } \\
\text { disease is an obvious } \\
\text { social disadvantage. There was also a } \\
\text { strong sense of shame. }\end{array}$ & $\begin{array}{l}\text { The nature of stigma that patients } \\
\text { experience is associated with certain } \\
\text { general fears and anticipation of rejection, } \\
\text { rather than the actual rejection that } \\
\text { patient truly experience from society. It } \\
\text { reduced marriage prospects for men } \\
\text { ( } 75 \% \text { ) and women ( } 59 \%) \text {. ZCL had no } \\
\text { positive effects on their lives. The } \\
\text { consequences have rather been negative. } \\
\text { About } 73 \% \text { suffered social exclusion and } \\
\text { stigmatization. Their relationships have } \\
\text { been broken and they face more } \\
\text { interpersonal conflicts in society, } \\
\text { regardless of the context (family, social or } \\
\text { professional). The consequences were } \\
\text { seen also in their chances of getting } \\
\text { employment }\end{array}$ \\
\hline
\end{tabular}

Ramdas-2016 Aesthetic stigma $38 \mathrm{CL}$ patients who reported having

(Surinam) In the literature:

1) experienced or

enacted stigma;

2) anticipated,

felt, or perceived

stigma; and 3)

internalized or

self-stigma

Reyburn-2000 Enacted stigma

(Afghanistan) Feeling rejection

and isolation experienced negative reactions related to

Health related stigma is linked to patients' own illness experiences

$\mathrm{CL}$ expressed feeling bad about their

looks. Some said they were "disgusted" by

their sores, others reported feeling "shy" or

"ashamed".

Some women expressed anger at the

situation Felling bring shame to the whole family. One girl said that she sometimes felt suicidal.
Women tended to express feelings of rejection and isolation more frequently than men Widespread and inappropriate fear of direct or indirect transmission of $\mathrm{CL}$ to others. Fear of contagion and an association with dirt, low personal hygiene, sinfulness and disgust. If you commit a sin or you have done something wrong, you will get the punishment from God later on. An insulting word, "soldana" was commonly reported to be used for $C L$ sufferers, leading to a general feeling of victimization. Some respondents were required to eat separately from the family with his/her own plate, cup, utensils and not to share a bed with healthy familymembers. Women with $\mathrm{CL}$ often reported that they were not allowed to cook for the family. Had lost authority or felt disempowered from interacting in public or managing their affairs. It seemed that the perceived need to isolate $C L$ sufferers from others readily

developed into a more personal rejection.
Reasons for Psychosocial burden

\author{
Feels shame. Fears of infecting their \\ children and infecting others through \\ food and drink. Fears of deformity, \\ disability and death. Fear of malignancy.
}

Emergence of psychological

consequences due to perceived stigma.

Respondents are dissatisfied with their self-image and appearance. Scars alter women's beauty (58\%) Drugs were seen to have little or no effect, and the risk of getting the disease again is likely. The more a person looks at the world anticipating

segregation and rejection, the more they perceive ZCL as a disease with harmful effects on them-The more they see it as a mysterious and

incomprehensible illness, and the more they talk about suffering and emotional difficulties.

These feelings were experienced when sores became bigger, or when they had multiple sores. The gruesome appearance of $\mathrm{CL}$ sores contributed to patients' fear of the disease. Aside from a sore's appearance, the growth of a sore, the increase in number of sores, and their visibility could also cause overt negative reactions from those in a patient's environment.

One of the major concerns for young people, especially women, was their appearance and adherence to an ideal of beauty. CL was felt to seriously undermine their prospects for marriage. Both active lesions and scars were a concern, particularly on the face. Several men reported that leishmaniasis caused problems in taking their ablutions and staying ritually clean throughout the prayer. They felt that others saw them as unclean and they were deterred from praying at the mosque. attitudes (negative or positive) society has towards the patient (Fig. 2).

The literature on burn injuries shows an adjustment over time independently of the injury size [63]. The possible change of self-perception with age is a matter of debate. For some people their self-concept could be stable but for others it could change in positive or negative ways [64, 65]; depending on the memories [66], on how emotions and memory interact and how these emotions change across lifespan $[67,68]$. 


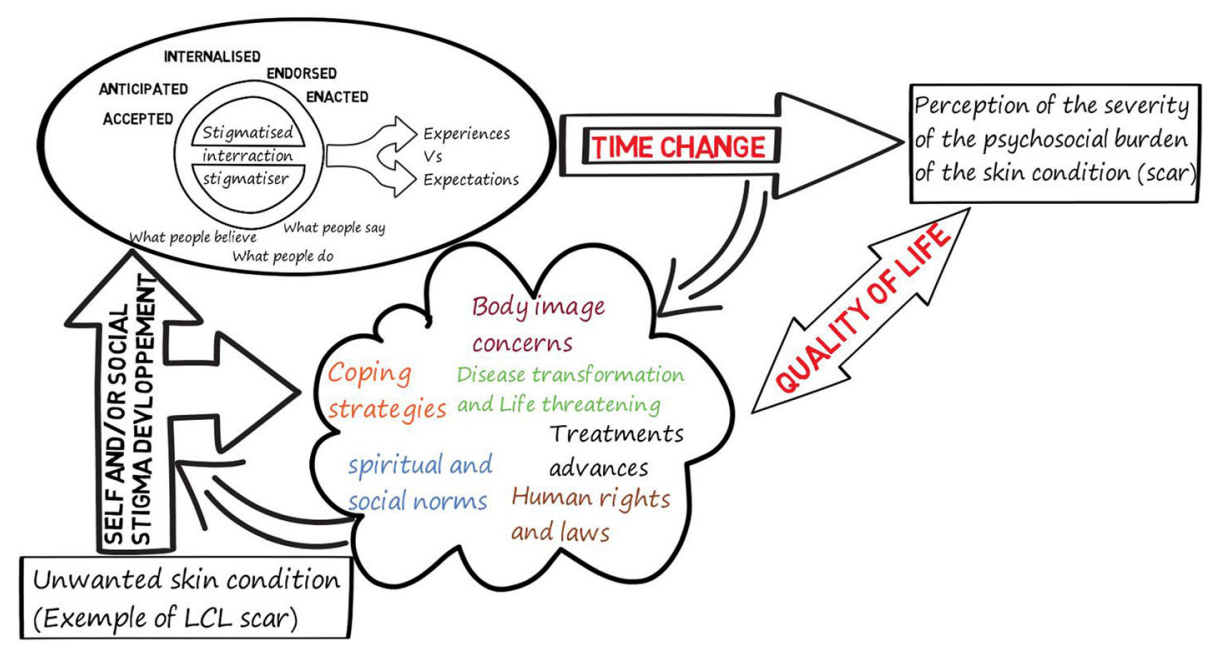

Fig. 2 Time adjustment of stigma types and psychosocial impact of unwanted skin conditions adapted from Deacon \& al [34]; Weiss [27]; and Thompson \& al [62] applied to Localised cutaneous leishmaniasis (LCL)

This scoping review can only be as strong as the studies it included, and in our case, there were some limitations. A small sample size characterized most of the included studies, and not all had appropriate control groups. E.g., the Kassi et al. [44] record is a case report presented at a symposium, telling the case of one woman with CL. The reports are not all of the same quality and are sometimes lacking detail. Reithinger et al. [42] is a short communication, describing summary results of a study that has not yet been fully published in an indexed journal. Most studies had descriptive crosssectional quantitative survey designs with one single participant contact. Not all studies distinguished the LCL lesion from the LCL scar, though there is evidence that the effect is not the same, and that even within LCL it depends on lesion type.

Future studies should pay more attention to potential confounding factors such as the physical aspect of the lesion or scar, the socio-economic position of the person with LCL and context related factors determining the CL-related knowledge, attitudes, and practices of society [69]. Indeed, lack of knowledge about this disease and its transmission patterns can lead to collective fears, which could fuel stigmatization, rejection, and isolation such as observed in Kabul, Afghanistan. A mixed methods approach is strongly advised, as so far in many endemic areas only quantitative patient surveys were done, leaving a lot of unanswered questions about the community perception. To enhance our understanding, we recommend the development of a standard validated stigma scale for CL. Furthermore, prospective follow-up studies will more accurately describe the time-dependent changes in perception. Future qualitative research should examine stigma and quality of life components from the perspective of the patient and the health care provider and give orientations for interventions.

Our review contains some limitations. Firstly, we acknowledge that we may have missed some relevant studies because of language restrictions that excluded large parts of the world where CL is common as well (especially articles published in Chinese and Russian). Secondly, as a common limitation of scoping reviews, we did not grade the quality of evidence, to avoid loss of information, but we may have included weak evidence in this way.

\section{Conclusion}

The literature on $\mathrm{CL}$ in the past 20 years claims that $\mathrm{CL}$ lesions, like it is the case in any other neglected infectious diseases related to poverty, influences the psychological state of those affected and can lead to a reduction in their quality of life and stigma [27, 70-75]. However, previous literature reviews assessing the burden of disease caused by leishmaniasis usually did not distinguish between the localized CL self-healing form and the other non-localised forms of CL (mucocutaneous, diffuse). Our review showed that most qualitative studies concur that LCL has indeed a negative effect on quality of life and mental health, through a process of social and self-stigmatization.

\section{Additional file}

Additional file 1: Log book, search history, excluded articles, included articles and Data extraction labels of the main conceptual categories. (DOCX $35 \mathrm{~kb}$ )

\section{Abbreviations}

BIS: Body Image Satisfaction scale; CL: Cutaneous Leishmaniasis;

DALYs: Disability-Adjusted Life Years; DLQI: Dermatology Life Quality Index; 
DSM-IV: Diagnostic and Statistical Manual of Mental Disorders, 4th. Edition; HAD: Hospital Anxiety and Depression scale; LCL: Localized form of cutaneous leishmaniasis; MeSH: Medical Subject Headings; NTD: Neglected Tropical Disease; PRISMA: Preferred Reporting Items for Systematic Reviews and Meta-Analyses; QoL: Quality of Life

\section{Acknowledgements}

N/A

\section{Funding}

No specific funding was received for this work. IB and ZB are supported by doctoral grants from the Belgian Directorate General for Development Cooperation and Humanitarian Aid. The funder had no role in the study design, data collection and analysis, decision to publish, or preparation of the paper.

\section{Availability of data and materials}

The datasets supporting the conclusions of this article are included in the article and its additional file.

\section{Authors' contributions}

$\mathrm{IB}, \mathrm{VB}$ and $\mathrm{MB}$ developed the idea for the paper. $\mathrm{IB}$ and $\mathrm{HS}$ conducted the literature searches. IB and ZB assessed citations. IB, ZB and $M B$ assessed the included records. All authors rechecked the inclusion and exclusion criteria of the selected records. IB, VB and MB wrote the first draft of the manuscript. All authors commented on the manuscript. All authors read and approved the final manuscript.

\section{Ethics approval and consent to participate}

We followed the relevant standards while conducting this review.

\section{Consent for publication}

Not applicable.

\section{Competing interests}

The authors declare that they have no competing interests.

\section{Publisher's Note}

Springer Nature remains neutral with regard to jurisdictional claims in published maps and institutional affiliations.

\section{Author details \\ ${ }^{1}$ National School of Public Health, Ministry of Health, Lemfedel Cherkaoui Street, Madinat Al Irfane, 10000 Rabat, Morocco. ${ }^{2}$ Department of Public Health, Institute of Tropical Medicine, Antwerp, Belgium. ${ }^{3}$ Department of Biomedical Sciences, Faculty of Pharmaceutical, Biomedical and Veterinary Sciences, University of Antwerp, Antwerp, Belgium. ${ }^{4}$ Vrije Universiteit Brussel, Rabat, Morocco. ${ }^{5}$ Department of Pathology and Veterinary Public Health, Hassan II Agronomy and Veterinary Institute, Rabat, Morocco.}

Received: 1 November 2017 Accepted: 6 March 2018

Published online: 15 March 2018

\section{References}

1. Karimkhani C, Wanga V, Coffeng LE, Naghavi P, Dellavalle RP, Naghavi M. Global burden of cutaneous leishmaniasis: a cross-sectional analysis from the global burden of disease study 2013. Lancet Infect Dis. 2016;16:584-91. Available from: http://www.ncbi.nlm.nih.gov/pubmed/26879176.

2. Balley F, Mondragon-Shem K, Hotez P, Ruiz-Postigo JA, Al-Salem W, AcostaSerrano A, et al. A new perspective on cutaneous leishmaniasis-implications for global prevalence and burden of disease estimates. PLoS Negl Trop Dis. 2017;11:e0005739. Available from: http://www.ncbi.nlm.nih.gov/pubmed/ 28796782.

3. Reithinger R, Dujardin J-C, Louzir H, Pirmez C, Alexander B, Brooker S. Cutaneous leishmaniasis. Lancet Infect. Dis. 2007;7:581-96. Available from: http://www.ncbi.nlm.nih.gov/pubmed/17714672.

4. Olliaro P, Grogl M, Boni M, Carvalho EM, Chebli H, Cisse M, et al. Harmonized clinical trial methodologies for localized cutaneous leishmaniasis and potential for extensive network with capacities for clinical evaluation. PLoS Negl Trop Dis. Public Library of Science. 2018:12:e0006141. Available from: http://www. ncbi.nlm.nih.gov/pubmed/29329311.
5. Chernyshov PV, Zouboulis CC, Tomas-Aragones L, Jemec GB, Manolache L, Tzellos T, et al. Quality of Life Measurement in Acne. Position Paper of the European Academy of Dermatology and Venereology (EADV) Task Forces on Quality of Life and Patient Oriented Outcomes (QoL and PO) and Acne, Rosacea and Hidradenitis Suppurativa (ARHS). J Eur Acad Dermatology Venereol. 2017. Available from: http://www.ncbi.nlm.nih.gov/pubmed/ 28898474

6. Stavrou D, Weissman O, Tessone A, Zilinsky I, Holloway S, Boyd J, et al. Health related quality of life in burn patients-a review of the literature. Burns. 2014;40:788-96. Available from: http://www.ncbi.nlm.nih.gov/ pubmed/24433939.

7. Finnerty CC, Jeschke MG, Branski LK, Barret JP, Dziewulski P, Herndon DN. Hypertrophic scarring: the greatest unmet challenge after burn injury. Lancet. 2016;388:1427-36. Available from: http://www.ncbi.nlm.nih.gov/ pubmed/27707499.

8. Pandya AA, Corkill HA, Goutos I. Sexual function following burn injuries: literature review. J. Burn Care Res. 2015;36:e283-93. Available from: http:// www.ncbi.nlm.nih.gov/pubmed/25423439.

9. Attoe C. Pounds-Cornish E. Psychosocial adjustment following burns: an integrative literature review. Burns. 2015;41:1375-84. Available from: http:// www.ncbi.nlm.nih.gov/pubmed/26359733.

10. de Zeeuw J, Omansen TF, Douwstra M, Barogui YT, Agossadou C, Sopoh GE, et al. Persisting social participation restrictions among former Buruli ulcer patients in Ghana and Benin. Small PLC, PLoS Negl Trop Dis. 2014;8:e3303. Available from: http://www.ncbi.nlm.nih.gov/pubmed/25392915.

11. Zeldenryk L, Gray M, Gordon S, Speare R, Hossain M. The use of focus groups to develop a culturally relevant quality of life tool for lymphatic filariasis in Bangladesh. Qual Life Res. 2014;23:299-309. Available from: http://www.ncbi.nlm.nih.gov/pubmed/23793443

12. Thomas C, Narahari SR, Bose KS, Vivekananda K, Nwe S, West DP, et al, Comparison of three quality of life instruments in lymphatic filariasis: DLQI, WHODAS 2.0, and LFSQQ. PLoS Negl. Trop. Dis. 2014:8:e2716. Available from: http://www.ncbi.nlm.nih.gov/pubmed/24587467.

13. Mousley E, Deribe K, Tamiru A, Davey G. The impact of podoconiosis on quality of life in Northern Ethiopia. Health Qual Life Outcomes. 2013;11:122. Available from: http://www.ncbi.nlm.nih.gov/pubmed/23866905.

14. Lilly E, Lu PD, Borovicka JH, Victorson D, Kwasny MJ, West DP, et al. Development and validation of a vitiligo-specific quality-of-life instrument (VitiQoL). J am Acad Dermatol. 2013;69:e11-8. Available from: http://www. ncbi.nlm.nih.gov/pubmed/22365883.

15. Gupta V, Sreenivas V, Mehta M, Khaitan BK, Ramam M. Measurement properties of the vitiligo impact Scale-22 (VIS-22), a vitiligo-specific qualityof-life instrument. Br J Dermatol. 2014:171:1084-90.

16. Senol A, Yucelten AD, Ay P. Development of a quality of life scale for vitiligo. Dermatology. 2013;226:185-90. Available from: http://www.ncbi.nlm. nih.gov/pubmed/23735515.

17. Thompson AR, Clarke SA, Newell RJ, Gawkrodger DJ. Vitiligo linked to stigmatization in British South Asian women: A qualitative study of the experiences of living with vitiligo. Br J Dermatol. 2010;163:481-6. Available from: http://www.ncbi.nlm.nih.gov/pubmed/20426784

18. Thompson AR, Kent G, Smith JA. Living with vitiligo: Dealing with difference. Br J Health Psychol. 2002;7:213-25. Available from: http://www. ncbi.n/m.nih.gov/pubmed/14596710.

19. Link BG, Phelan JC. Conceptualizing stigma. Annu Rev Sociol. 2001;363-85. Available from: http://www.annualreviews.org/doi/abs/10.1146/annurev.soc. 27.1.363.

20. Kalra S, Kelkar D, Galwankar SC, Papadimos TJ, Stawicki SP, Arquilla B, et al. The emergence of ebola as a global health security threat: from "lessons learned" to coordinated multilateral containment efforts. J Glob Infect Dis. 2014:6:164-77.

21. Van Bortel T, Basnayake A, Wurie F, Jambai M, Koroma AS, Muana AT, et al. Psychosocial effects of an Ebola outbreak at individual, community and international levels. Bull World Heal. Organ. 2016;94:210-4.

22. Sampogna F, Sera F, Abeni D. Measures of clinical severity, quality of life, and psychological distress in patients with psoriasis: A cluster analysis. J Invest Dermatol. Elsevier. 2004;122:602-7. Available from: http://www.ncbi. nlm.nih.gov/pubmed/15086541.

23. Dowlatshahi EA, Wakkee M, Arends LR, Nijsten $T$. The prevalence and odds of depressive symptoms and clinical depression in psoriasis patients: a systematic review and meta-analysis. J Invest Dermatol. Elsevier; 2014;134 1542-51. Available from: http://www.ncbi.nlm.nih.gov/pubmed/24284419. 
24. Wailoo K. Stigma, race, and disease in 20th century America. Lancet. 2006; 367:531-3. Available from: http://www.ncbi.nlm.nih.gov/pubmed/16473131

25. Goffman E. Stigma: notes on the management of spoiled identity, edition 2009. New York: Simon and Schuster, Inc; 1963.

26. Hotez PJ. Stigma: the stealth weapon of the NTD. PLoS Negl Trop Dis. 2008; 2:e230. Available from: http://www.ncbi.nlm.nih.gov/pubmed/18446206.

27. Weiss MG. Stigma and the social burden of neglected tropical diseases. PLoS Negl Trop Dis. 2008;2:e237.

28. Gupta MA, Gupta AK. Cutaneous body image dissatisfaction and suicidal ideation: mediation by interpersonal sensitivity. J Psychosom Res. 2013;75: 55-9. Available from: http://www.ncbi.nlm.nih.gov/pubmed/23751239.

29. Rumsey N, Harcourt D. Body image and disfigurement: issues and interventions. Body Image. 2004;1:83-97.

30. Gardiner MD, Topps A, Richardson G, Sacker A, Clarke A, Butler PE. Differential judgements about disfigurement: the role of location, age and gender in decisions made by observers. J Plast Reconstr Aesthet Surg. 2010; 63:73-7. Available from: http://www.ncbi.n/m.nih.gov/pubmed/19084486.

31. Bradbury E. Meeting the psychological needs of patients with facial disfigurement. Br J oral Maxillofac Surg. 2012;50:193-6. Available from: http://www.ncbi.nlm.nih.gov/pubmed/21440966

32. Scambler G. Stigma and disease: changing paradigms. Lancet. 1998;352: 1054-5. Available from: http://www.ncbi.nlm.nih.gov/pubmed/9759769.

33. Vogel $\mathrm{DL}$, Bitman $\mathrm{RL}$, Hammer JH, Wade NG. Is stigma internalized? The longitudinal impact of public stigma on self-stigma. J Couns Psychol. 2013 60:311-6. Available from: http://www.ncbi.n/m.nih.gov/pubmed/23421775.

34. Deacon H, Stephney I, Prosalendis S. Understanding HIV/AIDS stigma: a theoretical and methodological analysis. Cape Town: HSRC Press; 2005.

35. Grant MJ, Booth A. A typology of reviews: An analysis of 14 review types and associated methodologies. Health Info Libr J. Blackwell Publishing Ltd; 2009. p. 91-108. Available from: http://doi.wiley.com/10.1111/j.1471-1842.2009.00848.x.

36. Daudt HM, van Mossel C, Scott SJ. Enhancing the scoping study methodology: a large, inter-professional team's experience with Arksey and O'Malley's framework. BMC Med. Res. Methodol. 2013;13:48. Available from: http://bmcmedresmethodol.biomedcentral.com/articles/10.1186/ 1471-2288-13-48.

37. Arksey H, O'Malley L. Scoping studies: Towards a methodological framework. Int J Soc Res Methodol Theory Pract. 2005;8:19-32. Available from: http://www.tandfonline.com/doi/abs/10.1080/1364557032000119616

38. Peters MD, Godfrey CM, Khalil H, Mclnerney P, Parker D, Soares CB. Guidance for conducting systematic scoping reviews. Int J Evid Based Heal. 2015;13:141-6.

39. Moher D, Shamseer L, Clarke M, Ghersi D, Liberati A, Petticrew M, et al. Preferred reporting items for systematic review and meta-analysis protocols (PRISMA-P) 2015 statement. Syst Rev BioMed Central. 2015;4:1. Available from: http://systematicreviewsjournal.biomedcentral.com/articles/10.1186/ 2046-4053-4-1.

40. Reyburn H, Koggel M, Sharifi A. Social and psychological consequences of cutaneous leishmaniasis in Kabul, Afghanistan. Heal Int Partnersh with Nor Church Aid. 2000. Available from: http://www.afghandata.org:8080/xmlui/ handle/azu/4484.

41. Yanik M, Gurel MS, Simsek Z, Kati M. The psychological impact of cutaneous leishmaniasis. Clin Exp Dermatol. 2004;29:464-7. Available from: http://www. ncbi.nlm.nih.gov/pubmed/15347324.

42. Reithinger R, Aadil K, Kolaczinski J, Mohsen M, Hami S. Social impact of leishmaniasis, Afghanistan Emerg Infect Dis. 2005;11:634-636. Available from: http://www.ncbi.nlm.nih.gov/pmc/articles/PMC3320322.

43. Simsek Z, Ak D, Altindag A, Günes M. Prevalence and predictors of mental disorders among women in Sanliurfa, Southeastern Turkey. J Public Heal [Internet] 2008;30:487-493. Available from: https://doi.org/10.1093/ pubmed/fdn025

44. Kassi M, Kassi M, Afghan AK, Rehman R, Kasi PM. Marring Leishmaniasis: The Stigmatization and the Impact of Cutaneous Leishmaniasis in Pakistan and Afghanistan. PLoS Negl Trop Dis. 2008;2:3. Available from: http://www.ncbi. nlm.nih.gov/pmc/articles/PMC2569210.

45. Nilforoushzadeh MA, Roohafza H, Jaffary F, Khatuni M. Comparison of quality of life in women suffering from cutaneous leishmaniasis treated with topical and systemic glucantime along with psychiatric consultation compared with the group without psychiatric consultation. J Ski Leishmaniasis. 2010;1. Available from: http://jsl.mui.ac.ir/index.php/jsl/article/view/6.

46. Fernando SD, Siriwardana H, Guneratne K, Rajapaksa LC. Some sociological aspects of cutaneous leishmaniasis in patients attending a tertiary referral
Centre in Colombo, Sri Lanka. Int Health. 2010;2:69-74. Available from: http://www.ncbi.n/m.nih.gov/pubmed/24037054.

47. Abazid N, Jones C, Davies CR. Knowledge, attitudes and practices about leishmaniasis among cutaneous leishmaniasis patients in Aleppo, Syrian Arab Republic. East Mediterr heal J. 2012;18:7-14. Available from: http:// www.ncbi.nlm.nih.gov/pubmed/22360005.

48. Vares B, Mohseni M, Heshmatkhah A, Farjzadeh S, Safizadeh H, ShamsiMeymandi S, et al. Quality of life in patients with cutaneous Leishmaniasis. Arch Iran Med. 2013;16:474-7. Available from: http://www.ncbi.nlm.nih.gov/ pubmed/23906253.

49. Handjani F, Kalafi A. Impact of dermatological diseases on family members of the patients using family dermatology life quality index: a preliminary study in Iran. Iran J Dermatology. Tehran: Iranian society of Dermatology; 2013;16:128131. Available from: http://www.iranjd.ir/download.asp?code=IJD131666128.

50. Turan E, Kandemir H, Yesilova Y, Ekinci S, Tanrikulu O, Kandemir SB, et al. Assessment of psychiatric morbidity and quality of life in children and adolescents with cutaneous leishmaniasis and their parents. Postep Dermatologii I Alergol. 2015;32:344-8. Available from: http://www.ncbi.nlm. nih.gov/pmc/articles/PMC4692819.

51. Ramdas S, van der Geest S, Schallig H. Nuancing stigma through ethnography: the case of cutaneous leishmaniasis in Suriname. Soc Sci Med. 2016;151:13946. Available from: http://www.ncbi.nlm.nih.gov/pubmed/26802370.

52. Chahed MK, Bellali H, Ben Jemaa S, Bellaj T. Psychological and psychosocial consequences of zoonotic cutaneous Leishmaniasis among women in Tunisia: preliminary findings from an exploratory study. PLoS Negl Trop Dis. 2016;10: e0005090. Available from: http://www.ncbi.nlm.nih.gov/pubmed/27788184.

53. Bennis I, Thys S, Filali H, De Brouwere V, Sahibi H, Boelaert M. Psychosocial impact of scars due to cutaneous leishmaniasis on high school students in Errachidia province, Morocco. Infect Dis Poverty. 2017;6:46. Available from: http://www.ncbi.nlm.nih.gov/pmc/articles/PMC5383955.

54. Al-Kamel MA. Stigmata in cutaneous leishmaniasis historical and new evidence based concepts. Our Dermatology Online 2017;

55. Bennis I, Belaid L, De Brouwere V, Filali H, Sahibi H, Boelaert M. "The mosquitoes that destroy your face". Social impact of cutaneous Leishmaniasis in South-Eastern Morocco, a qualitative study. PLoS One. 2017;12. Available from: http://www.ncbi.n/m.nih.gov/pubmed/29261762.

56. Semeneh. The psycho-social impact of cutaneous Leishmaniasis on people infected by the disease. Master thesis Addis Ababa Univ. Sch. Soc. Work. 2012;

57. Costa JM, Vale KC, Cecílio IN, Osaki NK, Netto EM, Tada MS, et al. Aspectos psicossociais e estigmatizantes da leishmaniose cutâneo-mucosa. Rev Soc Bras Med Trop. 1987;20:77-81. Available from: http://dx.doi.org/10.1590/ S0037-86821987000200003.

58. Magalhaes HM, Costa JM, Costa RM, Franca F, Vale KC, Marsden P, et al. Information-related changes in attitude to mucocutaneous leishmaniasis of a population from an endemic region of the south of Bahia. Rev Soc Bras Med Trop. 1990;23:49-52.

59. Toledo Jr. AC, da Silva RE, Carmo RF, Amaral TA, Luz ZM, Rabello A. Assessment of the quality of life of patients with cutaneous leishmaniasis in Belo Horizonte, Brazil, 2009-2010. A pilot study. Trans R Soc Trop Med Hyg. 2013;107:335-6. Available from: http://www.ncbi.n/m.nih.gov/pubmed/23474473.

60. van 't Noordende AT, Kuiper H, Ramos Jr. AN, Mieras LF, Barbosa JC, Pessoa SM, et al. Towards a toolkit for cross-neglected tropical disease morbidity and disability assessment. Int Heal. 2016;8(Suppl 1):i71-81. Available from: http://www.ncbi.nlm.nih.gov/pubmed/26940312.

61. Weigel R. X. MMA. Genero e Leishmaniose Cut anea no Equador Rural: risco de doencca, gravidade e conseque ncias FIOCRUZ E, editor. Rio Janeiro. SciELO Books; 2000. Available from: http://books.scielo.org/id/45vyc/pdf/ barata-9788575413944-13.pdf.

62. Thompson A, Kent G. Adjusting to disfigurement: Processes involved in dealing with being visibly different. Clin Psychol Rev Pergamon; 2001. p. 663-82. Available from: http://www.ncbi.n/m.nih.gov/pubmed/11434225

63. Wiechman SA, Patterson DR. ABC of burns. Psychosocial aspects of burn injuries. BMJ. BMJ publishing Group; 2004;329:391-393. Available from: http://www.ncbi.n/m.nih.gov/pubmed/15310609.

64. Kleinspehn-Ammerlahn A, Kotter-Gruhn D, Smith J. Self-perceptions of aging: do subjective age and satisfaction with aging change during old age? J Gerontol Ser B Psychol Sci Soc Sci. Oxford University Press; 2008;63: P377-85. Available from: http://doi.org/10.1093/geronb/63.6.P377.

65. Demo DH. The self-concept over time: research issues and directions. Annu Rev Sociol. 1992;18:303-26. Available from: http://www.jstor.org/stable/ 2083456. 
66. Köber C, Habermas T. How stable is the personal past? Stability of most important autobiographical memories and life narratives across eight years in a life span sample. J Pers Soc Psychol. 2017;113:608-26. Available from: http://www.ncbi.nlm.nih.gov/pubmed/28333472.

67. Kensinger EA, Piguet $O$, Krendl AC, Corkin S. Memory for contextual details: effects of emotion and aging. Psychol Aging. 2005;20:241-50. Available from: http://www.ncbi.n/m.nih.gov/pubmed/16029088.

68. Ebner NC, Fischer $\mathrm{H}$. Emotion and aging: evidence from brain and behavior. Front Psychol. Frontiers media SA; 2014;5:996. Available from: http://www. ncbi.nlm.nih.gov/pubmed/25250002.

69. Egan M, Tannahill C, Petticrew M, Thomas S. Psychosocial risk factors in home and community settings and their associations with population health and health inequalities: a systematic meta-review. BMC Public Health. 2008;8:239-52. Available from: http://www.ncbi.nlm.nih.gov/pubmed/ 18631374.

70. Alvar J, Yactayo S, Bern C. Leishmaniasis and poverty. Trends Parasitol. 2006; 22:552-7. Available from: http://www.ncbi.n/m.nih.gov/pubmed/17023215.

71. Hofstraat K, van Brakel WH. Social stigma towards neglected tropical diseases: a systematic review. Int Health. 2016;8:i53-70. Available from: http://www.ncbi.nlm.nih.gov/pubmed/26940310.

72. Okwa OO. Tropical parasitic diseases and women. Ann Afr Med. 2007;6:15763. Available from: http://www.ncbi.nlm.nih.gov/pubmed/18354939.

73. Okwor I, Uzonna J. Social and economic burden of human leishmaniasis. Am J Trop Med Hyg. 2016;94:489-93. Available from: http://www.ncbi.nlm. nih.gov/pubmed/26787156.

74. Homsi YMG. Leishmaniasis: a forgotten disease among neglected people. Internet J Heal. 2009;11. Available from: http://ispub.com/IJH/11/2/9151.

75. Moya L, Alvar J. Enfermedades tropicales desatendidas estigmatizantes: una revisión sistemática. Med Soc. 2011;246-58. Available from: http://www. medicinasocial.info/index.php/medicinasocial/article/view/471.

\section{Submit your next manuscript to BioMed Central and we will help you at every step:}

- We accept pre-submission inquiries

- Our selector tool helps you to find the most relevant journal

- We provide round the clock customer support

- Convenient online submission

- Thorough peer review

- Inclusion in PubMed and all major indexing services

- Maximum visibility for your research

Submit your manuscript at www.biomedcentral.com/submit 